\title{
A Study on Relationship Between Learning Spaces and Activities of Jena Plan Education in The Netherlands
}

\author{
Yoshinori Kakino, ${ }^{1,}$, , Sien van Dam ${ }^{2}$ \\ ${ }^{1}$ Architecture, Science and Technology, Tokyo University of Science, Tokyo, Japan \\ ${ }^{2}$ Architecture, Architecture and the Built Environment, Delft University of Technology, Delft, Netherland \\ Email address: \\ y-kakino@rs.tus.ac.jp (Y. Kakino), a.m.f.vandam@tudelft.nl (S. van Dam) \\ ${ }^{*}$ Corresponding author
}

\section{To cite this article:}

Yoshinori Kakino, Sien van Dam. A Study on Relationship Between Learning Spaces and Activities of Jena Plan Education in The Netherlands. International Journal of Architecture, Arts and Applications. Vol. 6, No. 3, 2020, pp. 56-70. doi: 10.11648/j.ijaaa.20200603.14

Received: June 28, 2020; Accepted: August 17, 2020; Published: August 27, 2020

\begin{abstract}
This aim of this paper is to clarify the relationship between learning spaces and activities of Jena plan education in Netherlands. The results of this study are as follows. 1) A learning space of Jena plan education is consisted as "learning unit" what contains some classrooms and "learning square". Children's seat should be comprised with children in different age group (ideally, comprise 1 group with 4 children) inside a classroom. Place table used for instruction or children's seat in the center of classroom, and by centering around these furniture, secure blank space (floor area) to carry out circle conversation. Arrange remaining seats in a way that surrounds blank space for circle conversation, by placing them near vertical plane as much as possible in a circular form. In doing so, make sure to place them in a way so that children can see blackboard from each seat as much as possible. 2) The learning situation of Jena plan education is consisted by the combinations of 13 learning forms, such as 5 types of "circular type" in which conversation and learning are held communally with teacher and children forming a circle, 4 types of "simultaneous type" in which children in such space simultaneously share the same learning content, and 4 types of "individual learning type" in which children engage in learning by individual or small group. 3) With higher grade, an identity of children rises, and variations of using learning spaces increases. We can say that "Room" type shared space (learning square) in Jena Plan Education, is effective spatial planning method in creating various place-of-learning for children in spatial level outside of classroom space. Accelerating children's independence / independent learning. For "Room" type learning space, all spaces including classroom space and learning square are divided (connected) by "Door". For this reason, each learning space mutually maintains independent condition during normal time. "Independence" seen in this kind of "Room" type learning space functions effectively, when children engage in learning independent from teacher (independent learning). The analysis result of this research shows that linked rate between use rate of learning square and activity inside classroom increases as school year moves up, and at the same time confirms that children's degree of independence from teacher in learning square also increases.
\end{abstract}

Keywords: School, Jena Plan, Netherlands, Learning Spaces, Individual Learning

\section{Research Background and Purpose}

This in Japan in 1988, the Ministry of Education, Culture, Sports, Science and Technology proposed "In addition to simultaneous teaching, the future school education needs to be carried out in a diversified way by implementing a kind of education that can fully utilize uniqueness of individual children/student, such as incorporating educational teaching method, learning system, and teacher organization". Thirty years have passed since undergoing several educational reforms, and "independent/conversational deep learning" is now on its way to be implemented in primary and secondary schools in sequence from April, 2020 [1, 2]. However, since its specific educational method and learning space planning are entrusted to onsite teachers, the means of implementation is currently still at trial and error phase, causing distress and confusion among onsite teachers. In consideration of such onsite actual condition, a kind of guideline that can show how best to plan / design learning space that can correspond to various "independent / conversational learning" by catering to uniqueness / individual differences between each child/student, must be established in architectural planning. 
Given that, when we direct our attention to Netherlands (a developed country that implements individual education), we learn that diverse and unique education is practiced in each school, since "Freedom of Education" is guaranteed in Netherlands under Article 23 of its Constitution [3]. Among other educational systems, "Jena Plan Education" is recognized as a school education model equipped with various learning systems/learning teaching methods, since instead of just teaching subjects, its time schedule is comprised with "Learning activity form" in which learning is implemented by rotating 4 kinds of learning activity entailing "conversation", "work", "play", and "event" [4]. At the same time, we can greatly anticipate learning space in which these kind of learning are being practiced, to serve as one of learning space model upon implementing "independent / conversational learning" in Japan. Moreover, since Jena Plan Education has also attracted attention in Japan in recent years, the first ever Japanese Jena Plan School was opened in Nagano Prefecture in April, 2019, thus attracting media attention [5]. In light of such trend, the author intends to position Jena Plan Education as an educational system that can serve as one of guideline concerning ideal form of future school education aimed by Japan, specifically on the creation of learning space. However, although people's awareness toward Jena Plan Education has been increasing gradually, information concerning necessary educational space and the way school buildings ought to be established are still lacking, specifically, research from the perspective of architectural planning is virtually unknown by people. Accordingly, this research aims to identify the relation between learning space and form of activity by understanding the actual condition of learning activity and space usage by using elementary school in Netherlands that practices Jena Plan Education as an example, alongside obtaining architectural planning guideline for planning of learning space to implement Jena Plan Education. At the same time, it is also positioned to be used as one of design materials for creation of learning space that corresponds to "Independent/conversational deep learning" scheduled to be implemented in Japan.

\section{Research Summary}

\subsection{Research Method}

In this research we first outlined the characteristic of Jena Plan Education and trend related to school architecture in Netherlands. We then analyzed spatial composition and installation of space regarding Jena Plan School (hereinafter, "JS"), to understand the spatial characteristic of JS.

Next, we examined the relation between learning space and form of activity in JS, by analyzing children's form of activity inside JS by focusing on "Learning activity form".

\subsection{Survey Method}

This research targeted latest examples as much as possible, in consideration of grasping the trend of JS in recent years. In doing so, the scope of target was limited to years after 2000, in consideration of maturity level of school education. Examples of which sufficient information can be obtained for selection process such as architectural drawing, photos, and opening year were being selected, among 218 JS schools published in HP of Netherlands /Jena Plan Education Association (NJPV) (Figure 1). As the result, aside from classroom (hereinafter, "CR"), this research also targeted a total of 2 examples (Table 1, Figure 2), by using 1 example from "Type where LS is placed between classroom" and "Type where classroom and LS are lined up side by side" equipped with shared space called "Learning space (hereinafter, "LS"). In recent years, LS is also seen in various spaces in JS schools.

Survey was conducted regarding the following three categories:

1. Actual measurement of furniture inside school buildings to grasp the use conditions of space.

2. Behavior observation survey to grasp the details of children's daily learning/actual condition of daily living activity in each example (On full-day basis, researchers plotted the position of children/teachers every 5 minutes on a diagram).

3. Hearing toward teachers to grasp use condition of space and lecture content,

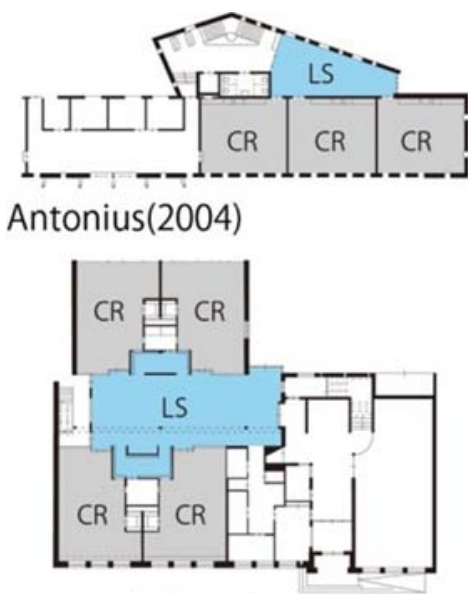

De Zwolle(2007)

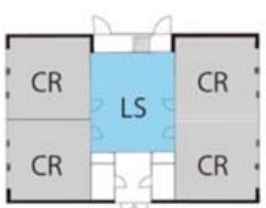

De Driestam(2008)

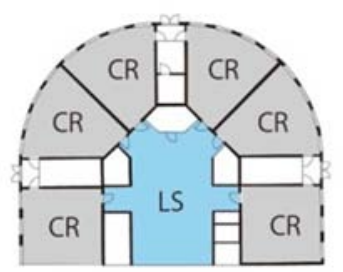

Sint Paulus(2008)

Figure 1. Cases of Jena plan school. 
Table 1. Outline of the survey cases.

\begin{tabular}{|c|c|c|c|c|c|c|c|c|c|c|c|c|}
\hline \multirow{2}{*}{ Case } & \multirow{2}{*}{$\begin{array}{l}\text { Opening } \\
\text { year }\end{array}$} & \multirow{2}{*}{ City } & \multirow{2}{*}{ Type of school } & \multirow{2}{*}{$\begin{array}{l}\text { Total floor } \\
\text { area } \mathbf{m}^{2}\end{array}$} & \multirow{2}{*}{ Floor } & \multirow{2}{*}{$\begin{array}{l}\text { Number of } \\
\text { pupils }\end{array}$} & \multirow{2}{*}{$\begin{array}{l}\text { Number of } \\
\text { classes }\end{array}$} & \multirow{2}{*}{ Age } & \multicolumn{4}{|l|}{ Group } \\
\hline & & & & & & & & & G-1,2 & G-3,4 & G-5,6 & G-7,8 \\
\hline ST & 2012 & Groningen & Brede school & 2894 & 2 & 200 & 8 & $4-12$ & & - & - & - \\
\hline KL & 2006 & Assen & Brede school & 5024 & 2 & 275 & 11 & $4-12$ & & - & & - \\
\hline
\end{tabular}

$\bullet=$ Target of act observation survey.

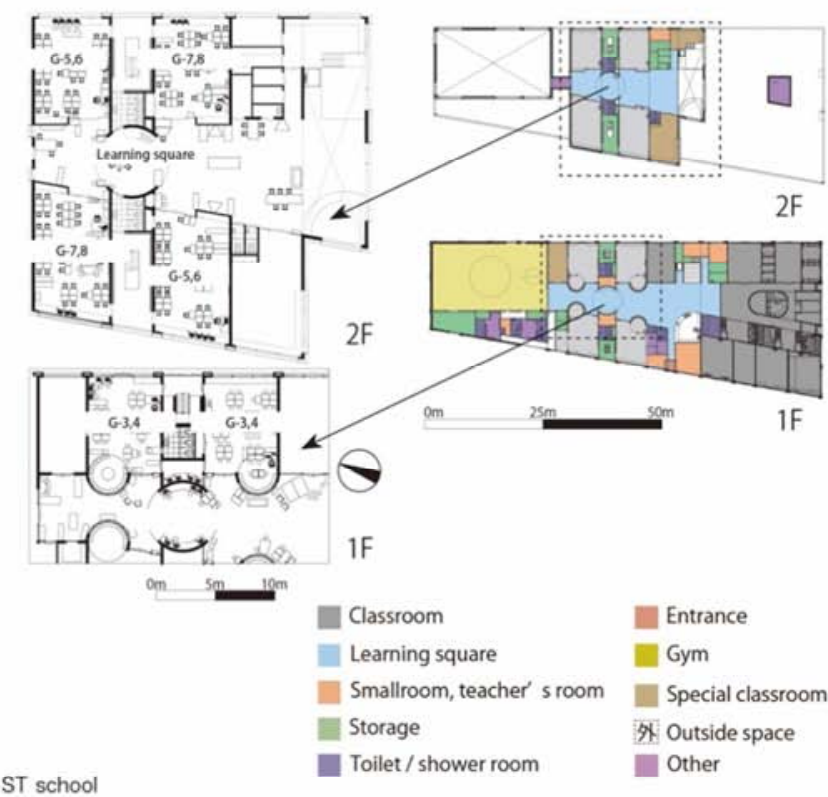

First floor is divided into 3 areas comprising common area with gymnasium in the center. school area with classroom and shared space in the center, and complex facilities. In this floor, rooms are placed in a way where various primary rooms are grouped together in each area. Specifically, one can see that in school area in the center. functions such as small room. storage space, and bathroom are placed in classroom as a single unit with shared space in the center. Since kitchen space and large stairs are incorporated in shared space. it has become a space that includes various functions. Dressing room and shower room are placed in gymnasium area. Only school area is placed in second floor, and in the same way as first floor, functions such as classroom, restroom, and storage space with shared space in the center are being set up as a single unit. Both floors are setup in a way where classroom is facing shared space.

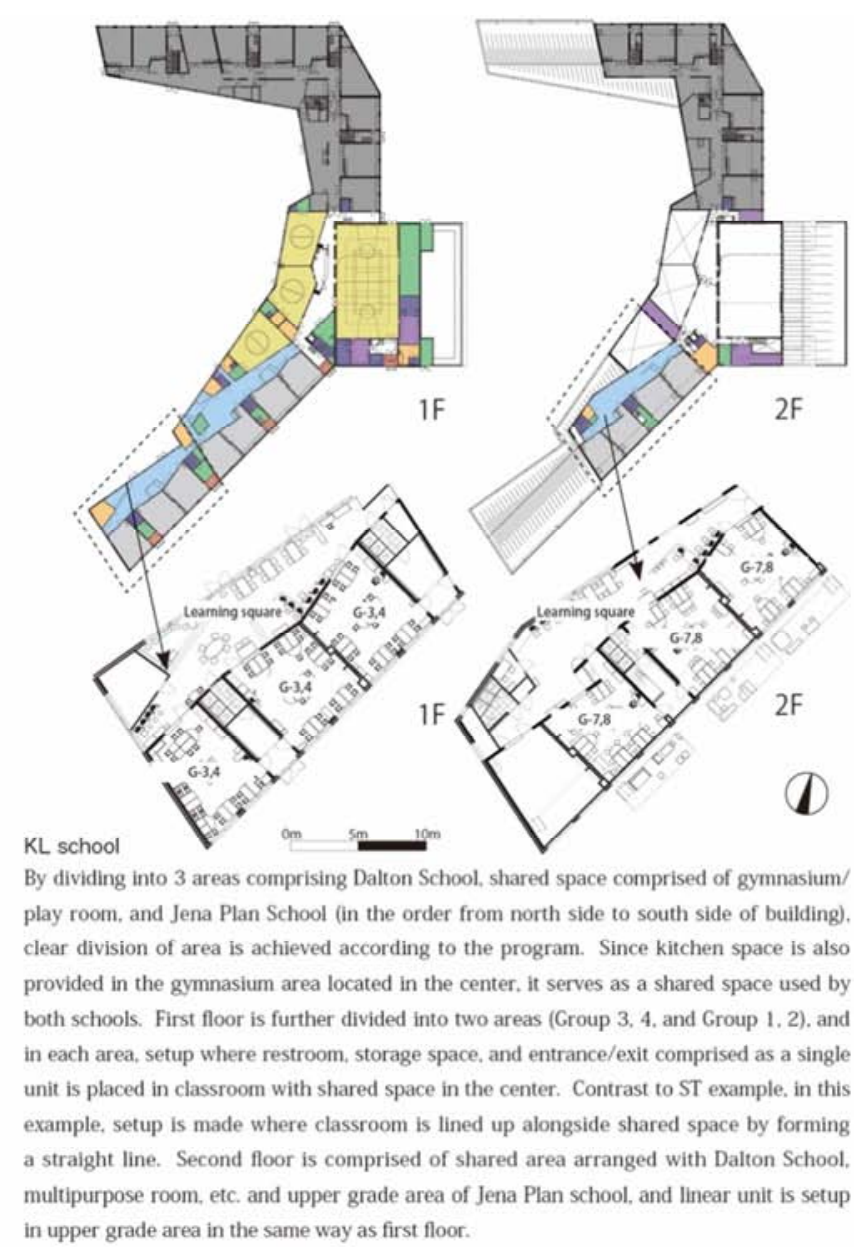

\section{$(1)$}

KL school provided in the gymnasium area located in the center. it serves as a shared space used by both schools. First floor is further divided into two areas (Group 3, 4. and Group 1.2). and in each area, setup where restroom, storage space, and entrance/exit comprised as a single unit is placed in classroom with shared space in the center. Contrast to ST example, in this example, setup is made where classroom is lined up alongside shared space by forming a straight line. Second floor is comprised of shared area arranged with Dalton School, in upper grade area in the same way as first floor

Figure 2. Plan of the survey cases.

\section{Jena Plan Education Summary}

\subsection{History Behind the Birth of Jena Plan, and Transition Accompanying Its Incorporation}

Jena Plan Education was proposed by a German philosopher Peter Peterson, (1884-1952), through the practice in pilot school at University of Jena. Basic idea regarding Jena Plan Education is mentioned in a book written by Peterson published in 1926 entitled "Chisanaienapuran (Der Kleine Jena-Plan)", which has earned the status of required reading for Jena Plan Education personnel until present [6].

Jena Plan was first introduced in Netherlands by Suus Freudenthal (1908-1986) who worked as secretary for liberal arts/educational reform research organization (WVO) that served as Netherlands branch of NEF in 1950's. Jena Plan Education expanded publically among education circles in
Netherlands, after WVO hosted a nationwide general conference with the theme (Educational Reform by Jena Plan) in 1964. During this conference, Freudenthal gave a lecture with the theme "Pedagogical/Organizational Structure at Jena Plan School" [7]. This WVO conference also served as a place to build relationship with people who assumed central role in subsequent Netherlands/Jena Plan Education activity, and in 1969 following this conference, "Jena Plan Education Foundation (SJP)" that centered around Jena Plan Education promoters was established, and efforts were made to popularize this education through development of educational method, teaching materials, etc.

Since then, under favorable institutional environment guaranteed by "Freedom of Education" stipulated in Article 23 of Constitution of Netherlands, Jena Plan Education achieved steady popularization/development, and it currently operates 220 Jena Plan elementary schools in Netherlands. 
Furthermore, Netherlands /Jena Plan Education Association (NJPV) was established in place of SJP in 1985, and various activity are being carried, among others, teaching materials development and teacher training, popularization of Jena Plan Education in other countries, etc. [8].

\subsection{Characteristic of Jena Plan}

Netherlands/Jena Plan rejects perceiving basic idea formulated by Peterson as a formal method (Method) as its basic approach, but instead promotes application/practice of content and method of education by sharing his basic idea as a "Concept", with educational personnel catering to individual situation. For this reason, Netherlands/Jena Plan Education Association (NJPV) devised its own "20 Principles of Jena Plan", and has made it clear that "Open Model" should be adopted as the general common approach of Jena Plan Education [9]. In 1991, association's nationwide general conference approved "20 Principles of Jena Plan" to be used as the official basic principle, and since then association participating schools are required to publish this 20 principles on school handbook distributed to guardians and people outside [10].

Characteristic of Jena Plan Education is mentioned in Table.

Grade levels are comprised of children in different age group. Although each grade levels normally comprises 3 school years, some schools comprise each grade levels in 2 school years. Grade levels are called "Foundational Group (Family Group)", and teacher in charge of grade levels is called "Group Leader"). Every year grade levels are being comprised at a new school year, with older children advancing to next group, and new younger children joining the group. As a general rule, Group Leader does not change. In terms of why it is advantageous to comprise grade levels with children in different age group, anticipation of development such as children being able to train ability to build human relations that reflects the real world by experiencing the position of youngest to oldest in order, developing independent /communal learning through learning environment where children can engage in stimulating interaction between one another, etc. are cited as some of the reasons.

For school activity, children engage in 4 basic activity (conversation/work (learning)/ play/ event (function) in a cyclical way. Conversation is held with participation of both children and teacher forming a circle. Work (learning) is generally divided into independent learning and communal learning, with addition of teacher conducting individual teaching and small group teaching as necessary. Although play activity has been planned in advance, various forms such as "free play" are being applied. Various events are held ranging anywhere from event held throughout the entire school such as presentation held at beginning and end of each week, to event held at a unit of each grade levels such as birthday party of teacher and children. Furthermore, in order to carry out these 4 activity in rotation, time schedule is created based on "Learning activity form" instead of based on subject, so that each time schedule can flexibly correspond to switching of activity.

\subsection{Trend of School Construction in Netherlands}

Opening of "brede school" is cited as the trend of school construction in Netherlands in recent years. "brede school" refers to a school system in which various programs that support child development are combined in a single building, such as school, children-rearing, social welfare, sports, physical therapy, culture, and library [11, 12]. Although combination of functions differs depending on region and school, in many examples, continuous education is being carried out that targets children between 0 and 12 years of age, by combining kindergarten/daycare center. By applying this system, consistent involvement of guardian can be achieved from pre-enrollment to end of elementary school. "Vensterschoo" (1995) that opened as the first ever "wide school" in Groningen Province in Netherlands in 1995 targets children between 0 and 15 years of age, and in addition to school facilities, it combines various programs such as pool, sports hall, day nursery, after-school care for children, and public library. Afterwards, the number of schools have increased rapidly, and roughly 500 schools that existed at the point of 2004, have increased to 2000 schools by 2014. As its breakdown, roughly 1600 secondary education schools, and 420 elementary education schools have been confirmed [13].

Herman Hertzberger (1932-) is one of modern architect who represents Netherlands for his reputation /career/ achievement. Moreover, he is also known as an architect who pursued the ideal form of architecture and urban space that center around human lifestyle, who together with Aldo Van Eyck (founder of structuralism of Netherlands) criticized functionalism oriented modern architecture of

Netherlands. In terms of architectural work, he has a great deal of achievements in "school construction", and has so far designed architecture of over 30 schools. Since logic behind structuralism attaching importance to perspective of "part to whole" is also being applied in school construction, various architectural methods are seen in schools such as segmentation of space by "movable partition wall", difference in floor level and pillar serving as the backbone of activity, installment of small room "architectural device", and "learning street" functioning as learning space by inlaying such architectural device and furniture in hallway. The details of such architectural methods are introduced in his book "Space and Learning" [14, 15].

\section{Spatial Composition of School Building}

\subsection{Spatial Element That Comprises School Building}

Each example can be categorized into a total of 11 types of components from the composition of each example, with $\mathrm{CR}$ and LS at the head of the list. Furthermore, when you 
pay attention to the spatial composition surrounding CR, you can see that integrated building group (unit) is being comprised with combination of functions such as storage space /bathroom/small room, etc. in several CR and single LS (Figure 2). Next, we will focus on "Connection of Components". When you make a diagram (Figure 3) that shows how components of each unit are being connected by making room as smallest unit, you can see that almost all of the rooms are connected by "door". Independence of each room can be obtained by opening/closing of door, and space with relatively large area such as learning square can become one of "rooms". Moreover, as a common feature among each example, one can easily access external space by using stairs from storage space next to $\mathrm{CR}$ in second floor.

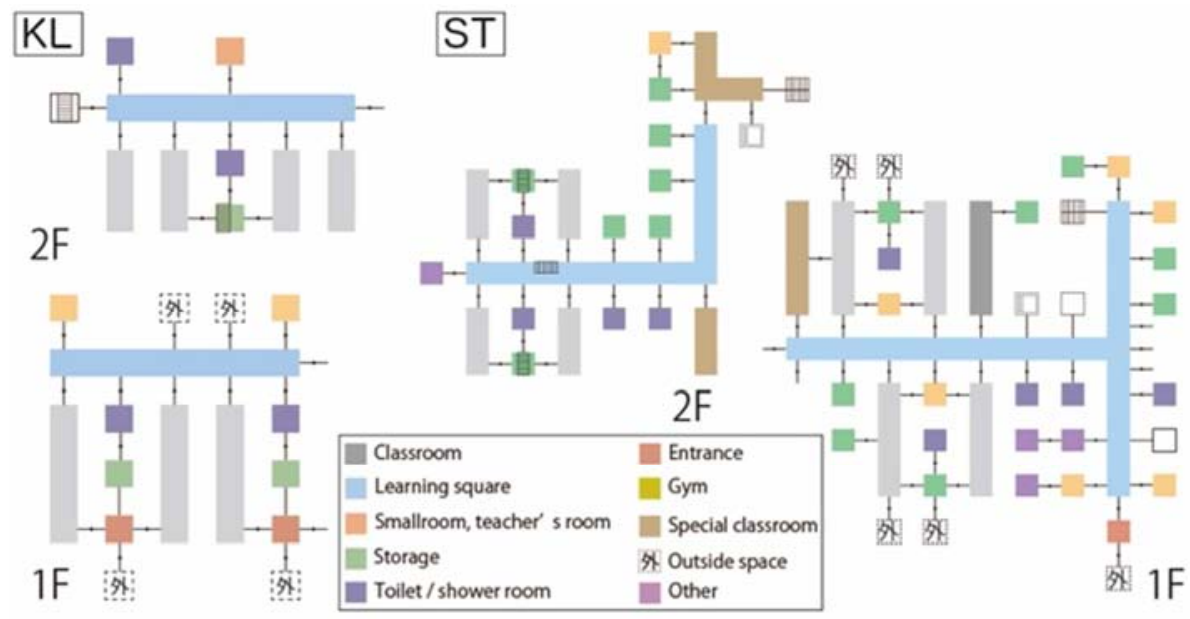

Figure 3. Spacial composition of the survey case.

\subsection{Installation of Classroom and Learning Square}

Next, when you look at spatial placements inside CR at JS (Figure 4), you can see that children's table is placed near the wall for CR at JS. The primary reason behind such placement is to smoothly move chairs when engaging in signature activity of Jena Plan Education called "circle conversation". Furthermore, the table section in the center is primarily used when teacher engages in teaching toward small number of

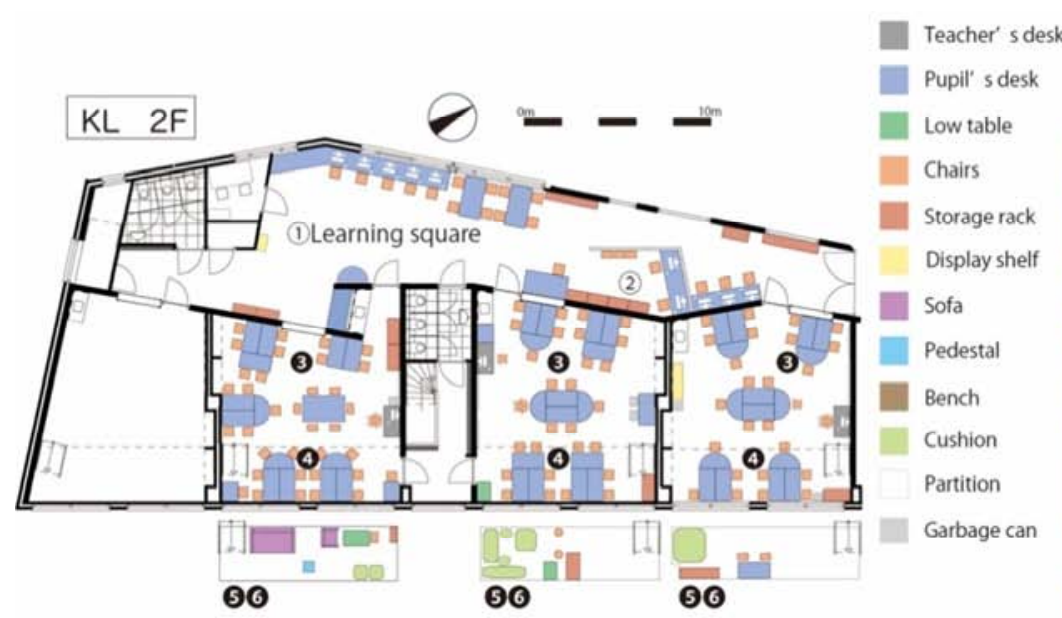

* Each class room is organized in different grades for example 5th and 6th. children by gathering some children (primarily based on school year unit). At Jena Plan Education, this kind of teaching method is called "Instruction".

Figure 5 indicates by-category number of furniture composition inside classroom. The Figure shows that the number of chairs larger than number of children are being secured for all grade levels.
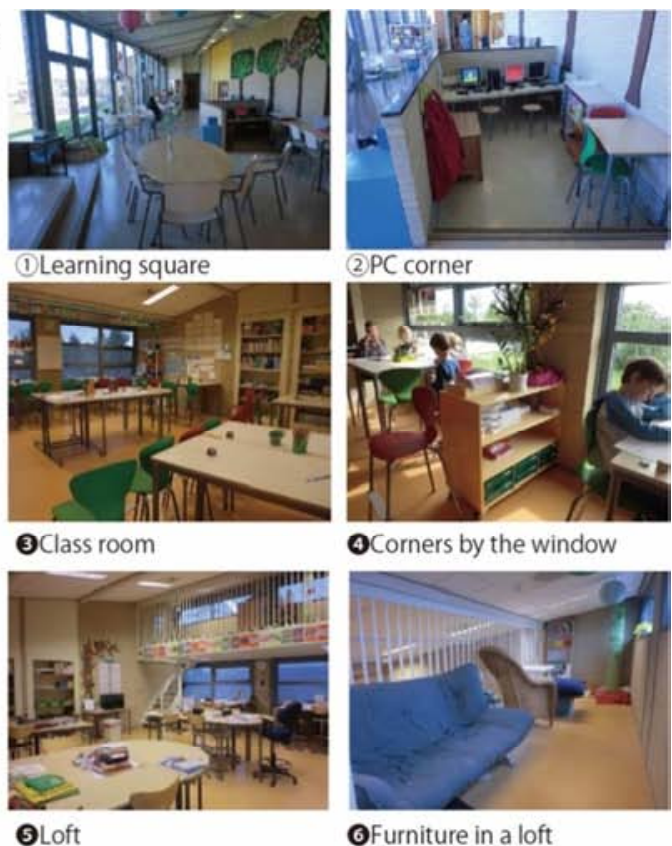

QCorners by the window

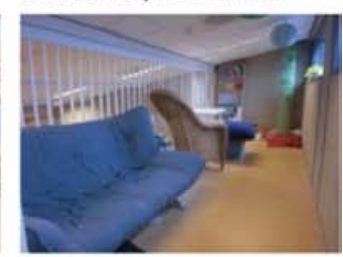

6Furniture in a loft

Figure 4. Furniture placement in classrooms and learning square. 
Specifically, G-7,8 in ST example has 65 chairs with a gap of 34 compared to the number of children, and G-3,4 has 31 chairs with a gap of 13 compared to the number of children, thus both examples largely exceed the number of children. This result is attributed to the fact that in these grade levels, round chairs are also being used together with seat type chairs, mainly during circle conversation session. Moreover, the number of desk and table are mostly determined according to the number of children. Although the number of storage furniture are reduced to half as the school year increased for KL example, in contrast, ST example shows trend of increase. Furthermore, we confirmed that many cushions are being used for upper grade in ST example, based on the installation of loft space.

Figure 6 indicates by-category number of furniture composition in learning square. The Figure confirms that in terms of furniture placed in each learning square, there are 8 types for 1FLS of KL, 8 types for 2FLS of ST, 8 types for 1FLS of KL, and 4 types for $2 \mathrm{~F}$ of KL. Regarding the number of composition of each furniture, we confirmed that storage furniture are set up in 15 locations for ST example in 1FLS, the largest number among examples. Furthermore, in terms of total number of furniture, 1FLS of KL example has the largest number of 67 furniture. As school year increased, the types and number of furniture declined. As the common phenomenon between both examples, the number of placed storage furniture declined as school year increased. Moreover, we confirmed that in St example the number of desk furniture declined and table furniture increased as school year increased, and in KL example desk furniture do not exist even though the number is declining, and that table furniture continue to be used even when school year increased.

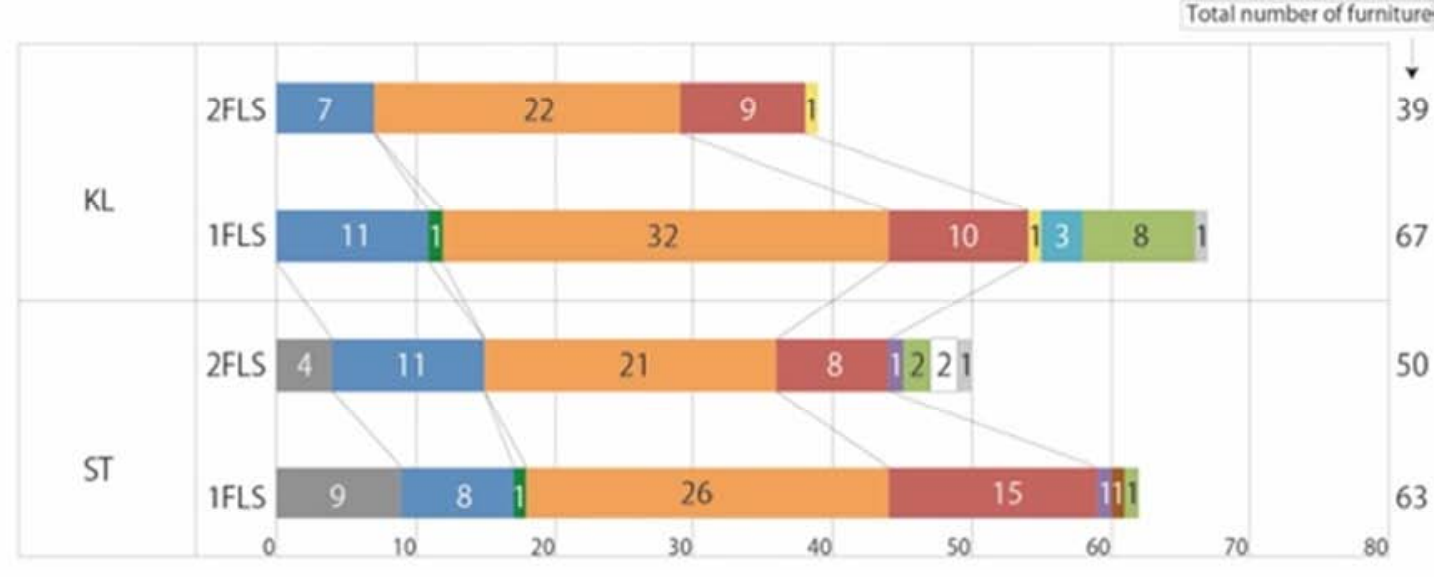

\begin{tabular}{|c|c|c|c|c|c|c|}
\hline Furniture & $\begin{array}{l}\text { Desk } \\
\text { Sofa }\end{array}$ & $\begin{array}{l}\text { Table } \\
\text { Pedestal }\end{array}$ & $\begin{array}{l}\text { low table } \\
\text { Bench }\end{array}$ & $\begin{array}{l}\text { Chair } \\
\text { Cushion }\end{array}$ & $\begin{array}{l}\text { Storage rack } \\
\text { Hand-wash }\end{array}$ & $\begin{array}{l}\text { Display shelf } \\
\text { Garbage box }\end{array}$ \\
\hline
\end{tabular}

Figure 5. Number of furniture inside classroom.

\subsection{Characteristic of Furniture Placement from the Standpoint of Relation Between Vertical Plane and Contact}

The analysis from the preceding section shows that furniture are being placed in a rather unique way, due to the fact that various types of furniture are being distributed. Since furniture are placed in both learning square and inside classroom by using vertical plane (wall surface/opening of school side, etc.) as one of the standard, such arrangement shows that Jena Plan Education places importance on relation between vertical plane and furniture placement.

Accordingly, in this section, we will focus on clarifying the characteristic of furniture placement from the standpoint of its relation to vertical plane, by conducting analysis focusing on contact relation between furniture and vertical plane (Figure 7). Figure 8 indicates the contact situation between furniture and vertical plane (wall surface/opening side, etc.) at each analysis area. As a whole, since majority of objects are in contact with furniture for both learning square and inside class room, strong relation between vertical plane and furniture placement is confirmed. When we look at inside the classroom of lower school year in ST example, we see that there are few vertical planes that function effectively as reliant location for furniture compared to other analysis area, due to installation of opening part, hand washing area, etc. Because of this, we are seeing low contact rate of furniture in this area. The overall result shows the largest number of short side contact type, followed by long side contact type, and independent type coming in last. In general, short side contact type in which long side direction is setup as primary use method and its opposite short side direction touching vertical side, is a type that enables use of table, etc. furniture by maximum amount of people. It is considered that contact relation with vertical plane is selected according to the scale of group (individual/pair/group) that uses furniture. When we look at 
each analysis area, the same number of contact is confirmed in long side/short side for ST1F, and a single contact is confirmed for independent type. It is considered that a kind of furniture placement in consideration of securing of flow space, positional relation with other furniture, etc. is being implemented. For ST2F, independent type is being applied actively in addition to short side contact type, and place that can correspond to use by not just individual/pair but also by group with at least 2 people are being installed. For KL1F, although 3 types of contact relation is seen in relation to 8 total furniture, the total number of furniture have declined dramatically to 3 furniture in $2 \mathrm{~F}$, and among them, short side contact type is seen in 2 locations.

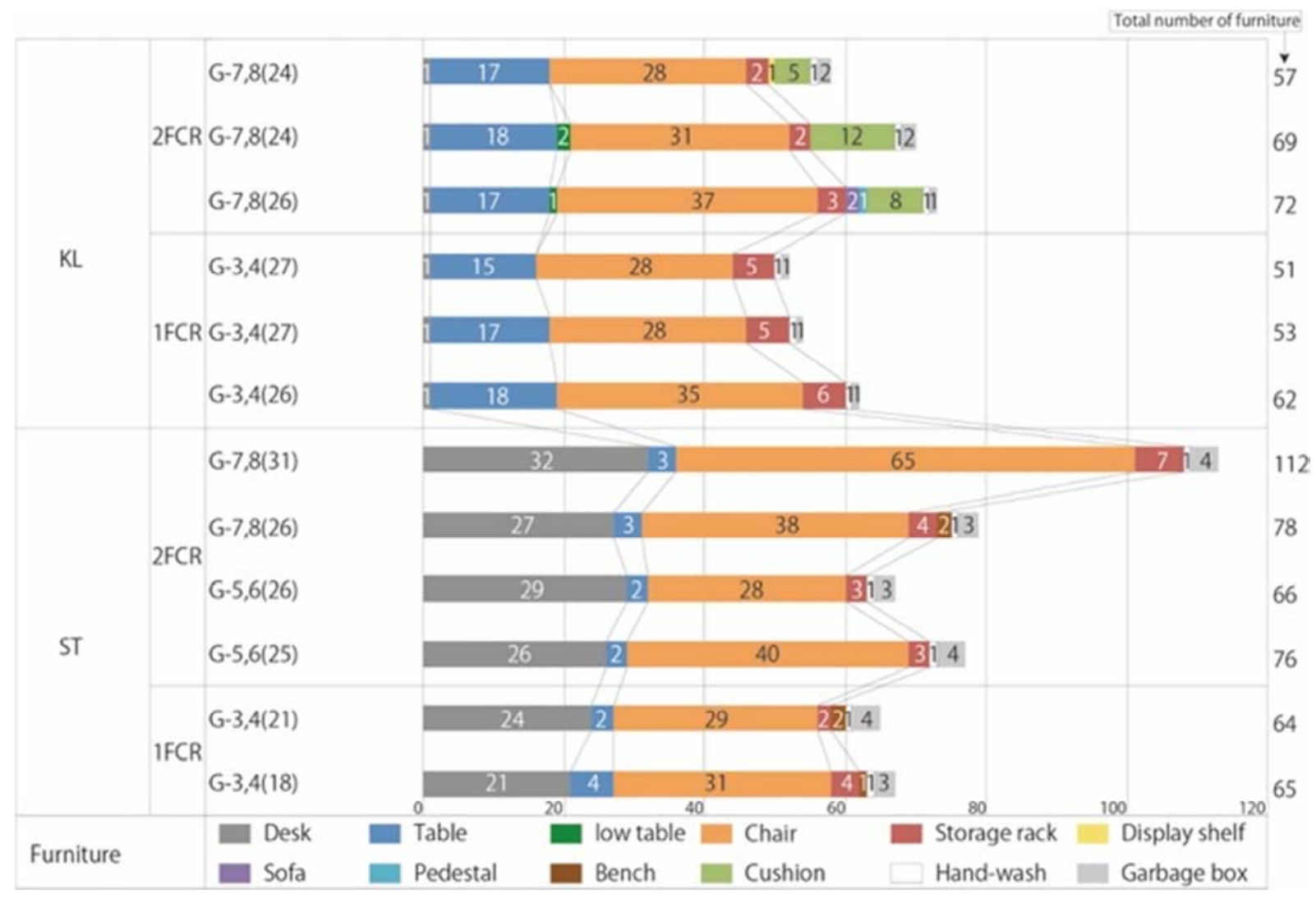

Figure 6. Number of furniture inside leaning square.

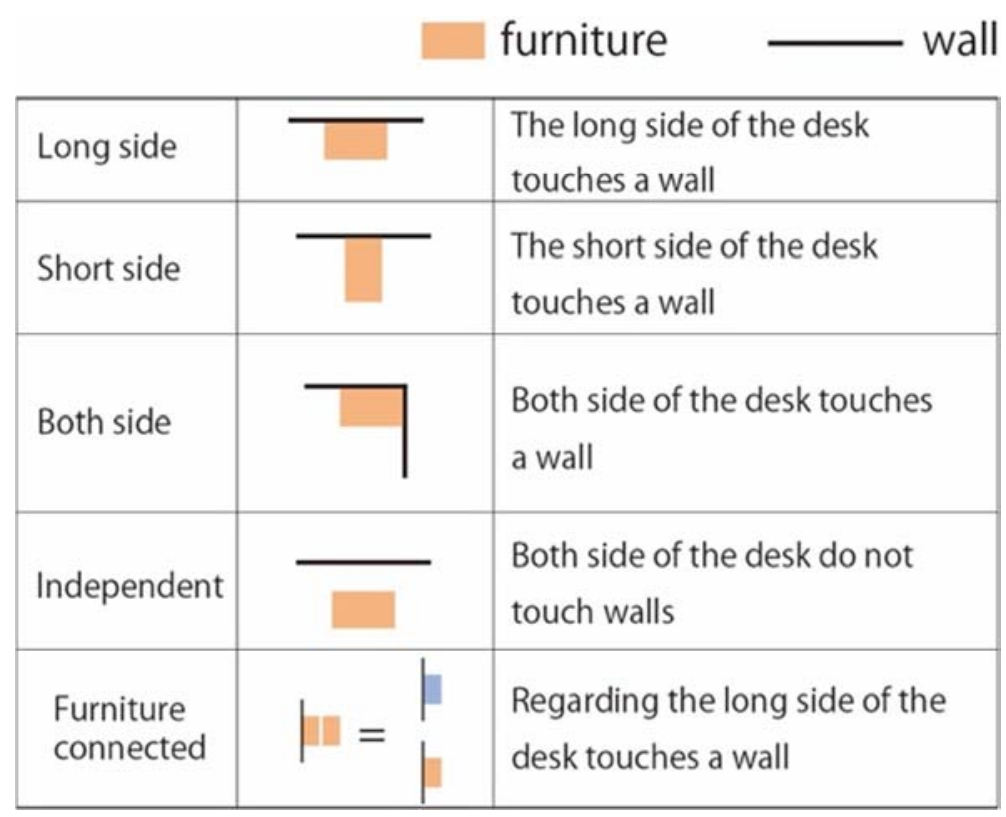

Figure 7. Types of furniture placement. 


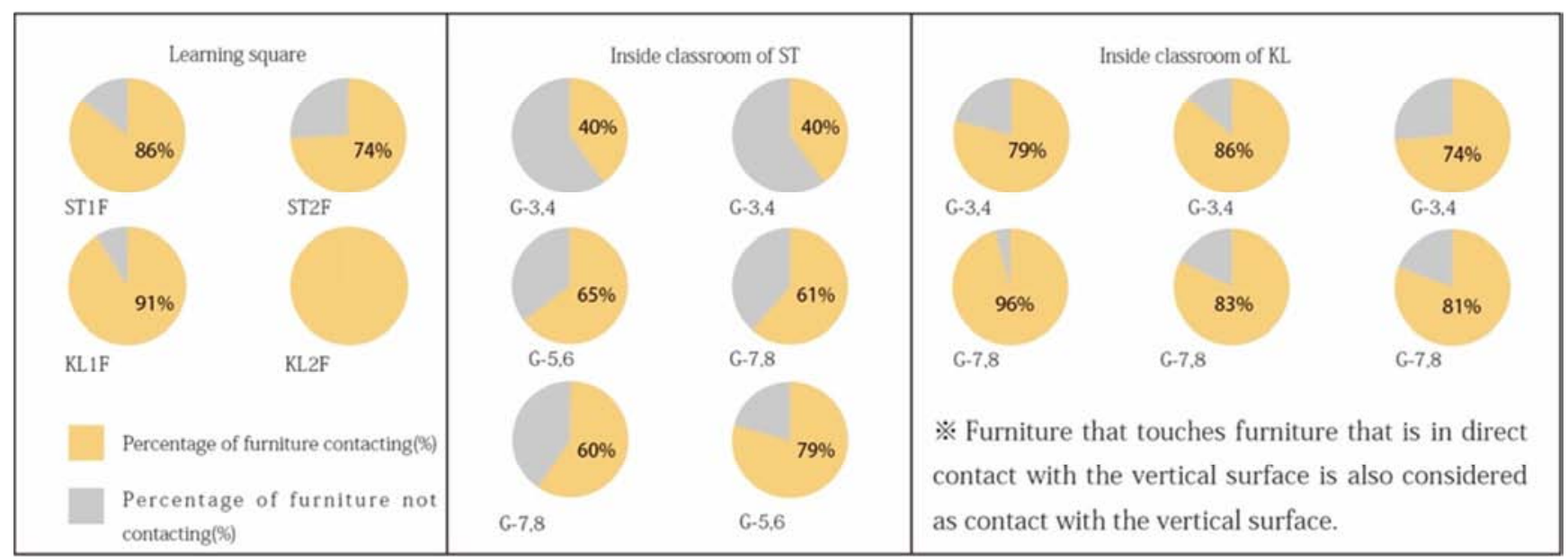

Figure 8. Ratio of furniture placement.

\section{Example of Daily Lesson Development of Jena Plan}

In this section, we will focus on how daily lesson is being advanced by looking at G-3,4 of KL school as an example (Figure 9). Table 2 indicates outline of Jenaplan education. The following common feature is seen, when we focus on learning activity flow from the analysis result. Namely, morning activity are comprised with the flow of always starting out with circle conversation, then moves onto self-study type activity such as math, followed by fruit time, small break, and reading time. Furthermore, world orientation and free activity time are held during afternoon. Jena Plan Education comprises the flow of activity according to the biorhythm of child. For example, self-study activity that require focus is held in morning, and activity that provide change of pace, such as light meal and outdoor play are held afterwards. Activities such as world orientation and art that entail a lot of interaction between children are held during afternoon, a time in which children's focus level start to decline after eating lunch. The characteristic of these kind of flow of activity are also confirmed in the example of this survey. All conversational activity in this survey are confirmed inside classroom. Table 3 indicates representative activities observed. Furthermore, all 4 types of activity are confirmed inside classroom. Play activity are confirmed in every locations, with a high ratio shown in locations outside of school. This is due to the fact that children use break time as a time of play activity. We confirmed that playroom is being used as primary activity space for event activity. For learning space, we confirmed that it was used as a space to primarily engage in work activity.

These results show that in Jena Plan Education, classroom is positioned as the primary space to conduct conversation/work activity.

Table 2. Outline of Jenaplan education.

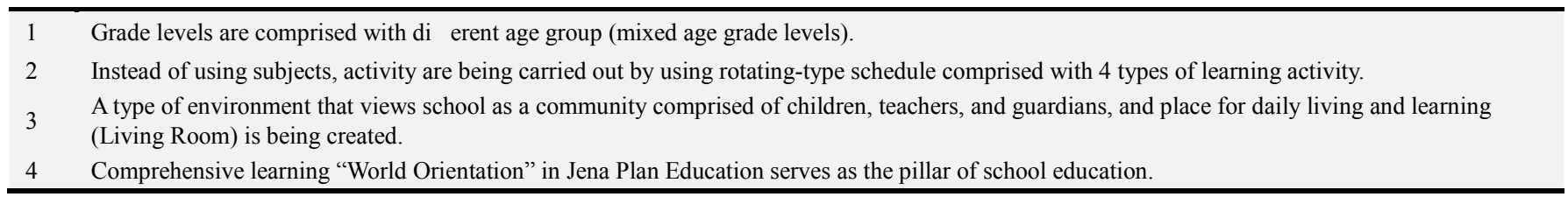

Table 3. Subjects in Jenaplan education.

\begin{tabular}{lllll}
\hline Dialogue & Work & & & Event \\
\hline Circle dialogue & Math & Self study & Block period & Event \\
Fruit time & Dutch & Spelling & Birthday party \\
News circle & & Geography & Video & Awards ceremony \\
Book reading & & WO & Diary & Play \\
Meeting & Play & & Dialogue+work & Work+play \\
Lunch & Outside & Theater & English & Craft \\
Closing greeting & Physical education & Gymnastics & Preparation for events & Free time \\
\hline
\end{tabular}




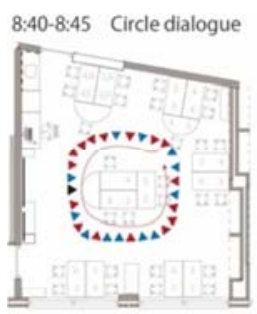

The representative pupil introduces what he recently bought (personal property).

13:05-13:10 Reading

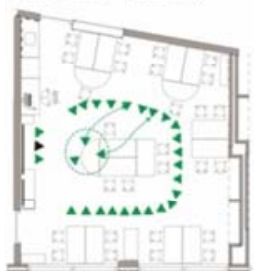

Each pupil reads books in a circle. Some pupils look for books for reading.

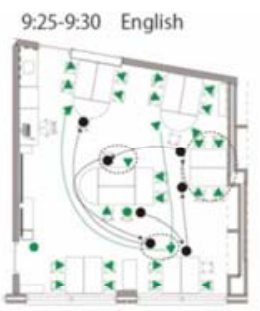

Each pupil draws at their own seat. The teacher goes around each child and provide individual guidance.

13:30-13:35 Math

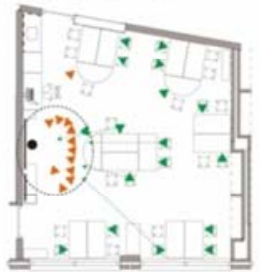

Simultaneous classes are held for 4 th grade pupils. Some of the Group 3 pupils are watchingit from their seats.

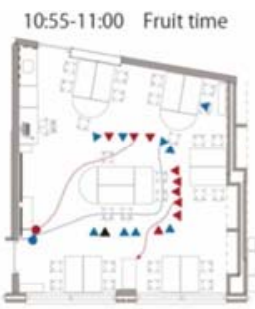

After a break, all pupils eat fruit during watching video on the electronic blackboard.

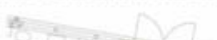

14:10-14:15• free time

$$
\therefore \text { puzzles }
$$

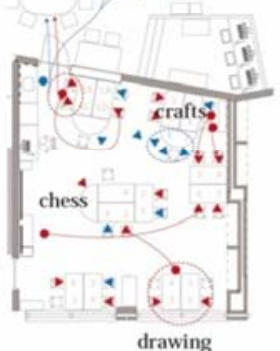

11:25-11:45 Dutch

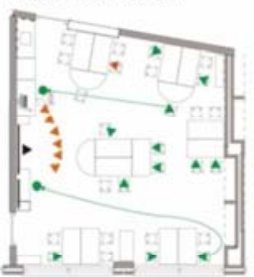

The teacher gathers some pupils in front of the electronic blackboard and gives instructions.

\section{4:25-14:30 Circle dialogue}

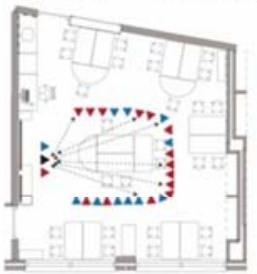

The teacher asks the pupils, and they raises their hands and speak one by one.

Teacher $\square$ Boy Girl $\square$ Pupil performing individual activities $\quad$ Pupil during special lesson

Figure 9. Daily lesson development of $G-3,4$ of $K L$ school.

\begin{tabular}{|c|c|c|c|c|}
\hline Lecture type[C1] & Dialogue type[C2] type[C] \\
\hline A teacher explains and gives & Teachers and students ask and \\
the same content to all children speak to each other and discuss
\end{tabular}

Lecture type[M1]
A teacher explains and gives Teachers and students ask and
the same content to all children. speak to each other and discuss.

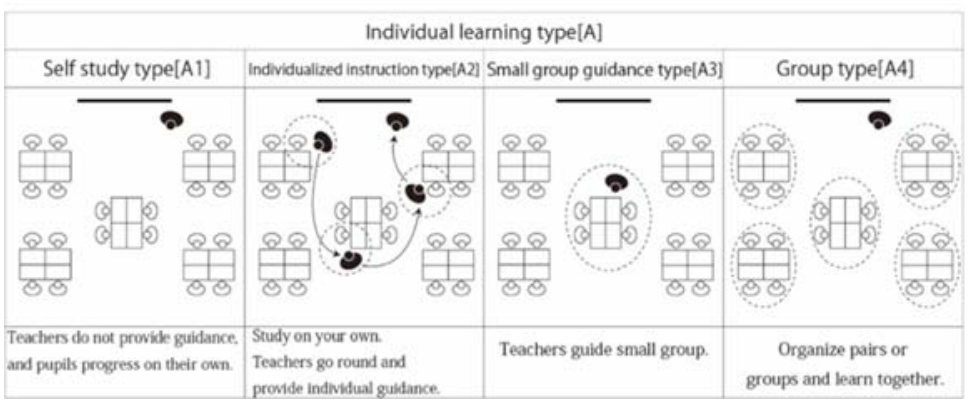

Figure 10. Types of learning system inside classroom. 


\section{Learning System Inside Classroom}

\subsection{Type of Learning System}

When we consider the actual condition of daily learning from the result of behavior observation survey, learning system carried out by CR of each unit can be categorized into a total of 13 types (Figure 10). Namely, they are 5 types of "circular type" in which conversation and learning are held communally with teacher and children forming a circle, 4 types of "simultaneous type" in which children in such space simultaneously share the same learning content, and 4 types of "individual learning type" in which children engage in learning by individual or small group.

\subsection{Ratio of Daily Learning System}

Figure 11 indicates the level of ratio seen on daily basis in the above learning system.

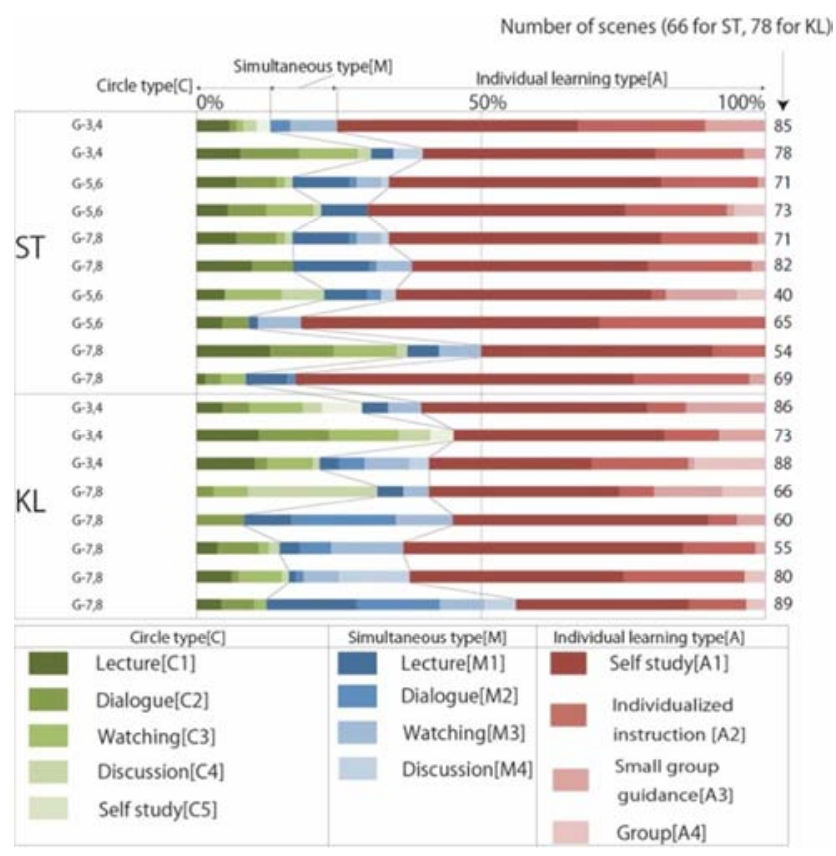

Figure 11. Ratio of daily learning system inside classroom.

It should be noted that Figure 11 only tallied the scene that used inside of CR among scene gathered on daily basis (66 for ST, 78 for KL), which counted all of applicable learning system pertaining to behavior data based on 5 minutes per 1 scene. For learning system, a high ratio of circular type was seen in G-3,4 in which a high ratio of conversational type and viewing type were recognized. G-3,4 of KL indicates a high

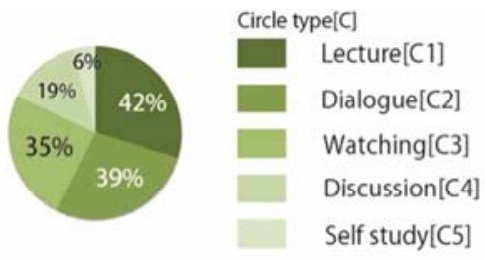

ratio of circular type, with no confirmation of simultaneous type. On the other hand, upper grade levels shows a higher ratio of simultaneous type than circular type, such as G-7,8 of ST and G-7,8 of KL. In contrast, since G-7,8 of KL revealed that circular type has largely exceeded simultaneous type, it is difficult to determine a steady trend between school years. The ratio between circular type and simultaneous type is considered to fluctuate each time by class unit, regardless of school year. Individual learning type made up the majority of learning system for all classes, and among such type, a highest ratio was seen in self-study type, followed by individual teaching type, and then small group teaching type. Based on such findings, we can perceive that Jena Plan Education trends to place importance on children's independent learning. Moreover, since we can find teacher's intention to select teaching method according to the development of each child from teacher's comment shown in Table 4, such engagement can be considered as one of the factors behind daily fluctuation of learning system.

Table 4. Teachers' comments about choice of teaching method.

\begin{tabular}{ll}
\hline $\begin{array}{l}\text { ST G-5,6 } \\
\text { Homeroom } \\
\text { teacher }\end{array}$ & $\begin{array}{l}\text { "There are still children who are not accustomed to } \\
\text { self-study in the table group and have not developed enough } \\
\text { independence." } \\
\text { "Because Group5,6 is also the preparation stage of }\end{array}$ \\
KL G-5,6 & $\begin{array}{l}\text { Group7,8, the class is assumed for Group7,8 and the } \\
\text { children are trained. Today, children were trying to solve } \\
\text { their own problems by intentionally reducing the number of } \\
\text { teacher }\end{array}$ \\
& $\begin{array}{l}\text { patrols." } \\
\end{array}$
\end{tabular}

\subsection{Ratio of Learning System in Relation to the Number of Counts for Overall System}

Figure 12 indicates the level of ratio of above each learning system in relation to the number of counts for overall system. Since the ratio between lecture type, conversation type, and viewing/listening type are at the same level for circular type, it shows that learning activity are being selected for wide range of things.

A large number of lecture type and viewing/listening type are seen in simultaneous type, thus showing that Jena Plan Education tends to actively incorporate viewing/listening type at the same level of ratio as above circular type. Self-study type makes up the majority for individual learning type, in the same way as the ratio of daily learning system. From the overall perspective, extremely low frequency of occurrence is shown in small group teaching type and group type.
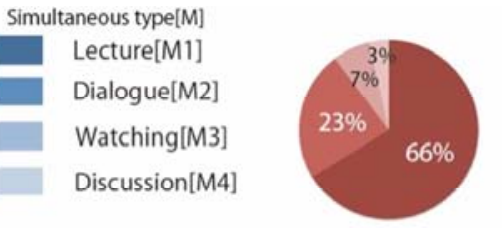

Individual learning type[A]

Self study[A1]

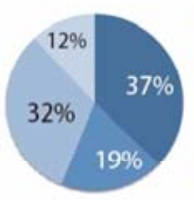

Discussion[M4]

Individualized instruction [A2]

Small group guidance[A3]

Group[A4]

Figure 12. Ratio of learning system inside Learning Square. 


\subsection{Ratio of Learning System from Perspective of By-learning Activity}

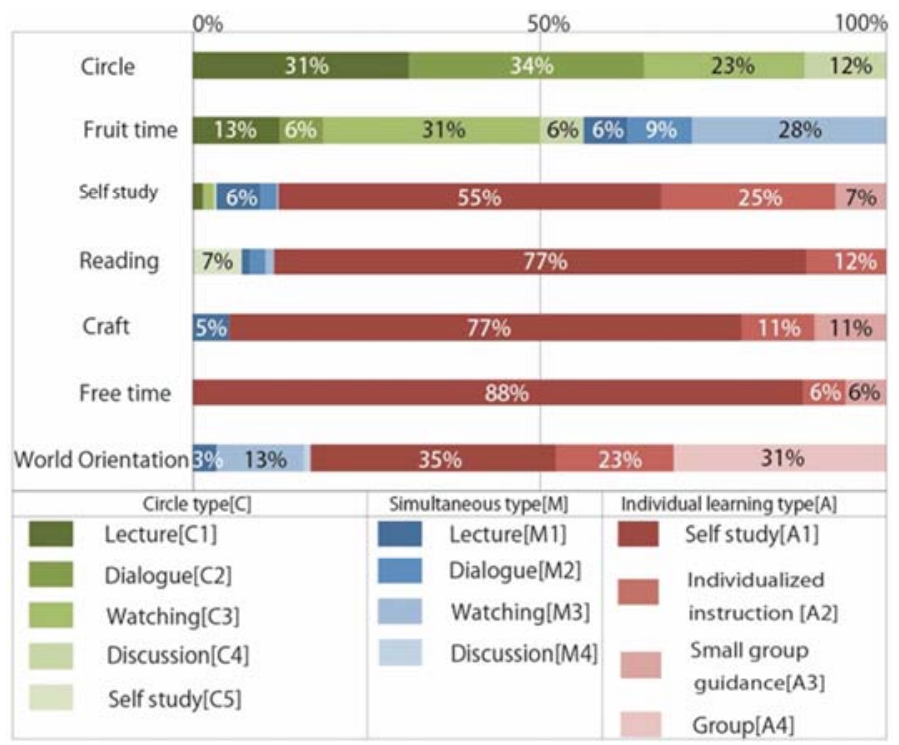

Figure 13. Ratio of learning system in each learning activity.

In this section, we will analyze what kind learning system combination is being used to comprise learning activity inside of CR. Upon conducting analysis, we categorized learning activity obtained from behavior observation survey result, and compiled them in table 4. Among them, since math, national language, spelling, self-study, and block period have similar form of activity, we compiled them into a single category by defining them as "self-study type activity". Figure 13 indicates representative type of composition ratio of learning system for learning activity. Figure 13 shows that all of learning system for circle conversation are comprised by circular type, and that its composition ratio is also similar to composition ratio of circular type indicated in 6.3. Fruits time activity shows occurrence of both circular type and simultaneous type, thus revealing that they both have the highest ratio of viewing/listening type. This is because students watch video, etc. on electronic blackboard while eating light meal. Although a small number of children, occurrence of circular type is seen in self-study type activity and reading. Specifically, children engage in reading through self-study type.

For world orientation (hereinafter, "WO"), alongside self-study type, a high ratio was seen in group type with overall low ratio.

\subsection{Ratio of Learning System from Perspective of By-learning Activity}

In the LS, similar to CR, the learning mode is categorized. Note that the 1FLS of the case ST is significantly different from the other cases in the spatial configuration and the state of segmentation of the space. According to the results of the behavior observation survey, there were only four individual learning types in the LS of each unit. In other words, LS in JS is not used for the activities of a large number of children or students, such as rallying during the school year as in Japanese elementary schools with OS, but for individual learning such as learning alone or in small groups. Used as a specialized space. Instructors' comments on the use of LS indicate that LS places emphasis on the use of LS, such as dealing with individual children and learning together (Figure 14).

Figure 15 shows the percentage of the above learning modes found in the LS. The frequency of using LS varies greatly from class to class, but self-study is the majority in all classes except G-7,8 (wolf) for ST and G-3,4 (chestnut) for KL. Next, individual-type outbreaks were observed in many classes, with group-type outbreaks being the fewest, with only G-5,6 (monkeys) in ST and G-7,8 (dill) in KL.

Here, we will extract the learning activities performed in the LS that are linked to the activities in the CR, and clarify where in the LS the learning activities were used and in what learning form. Comparing the activity linkage rate with the classroom in each case, the lower grade unit KL1FLS of Case KL shows a low value of $26 \%$, whereas the higher grade unit KL2FLS of the same case has $70 \%$, Higher grade unit ST2FLS shows a high value of $68 \%$ (Figure 16). From this, it is understood that $\mathrm{CR}$ and LS are used in conjunction with each other as the grade increases, and the range of children's use of space tends to expand. Focusing on the relationship between learning activities, learning styles, and places of use, self-study activities are performed in many places in the LS (Figure 17), and the use of small-group guidance [A3] can be confirmed at the table corner. The cushion corner can be used for reading only, and the floor is used as an activity area during free time. In addition, it can be confirmed that the PC corner is used for many learning activities. 


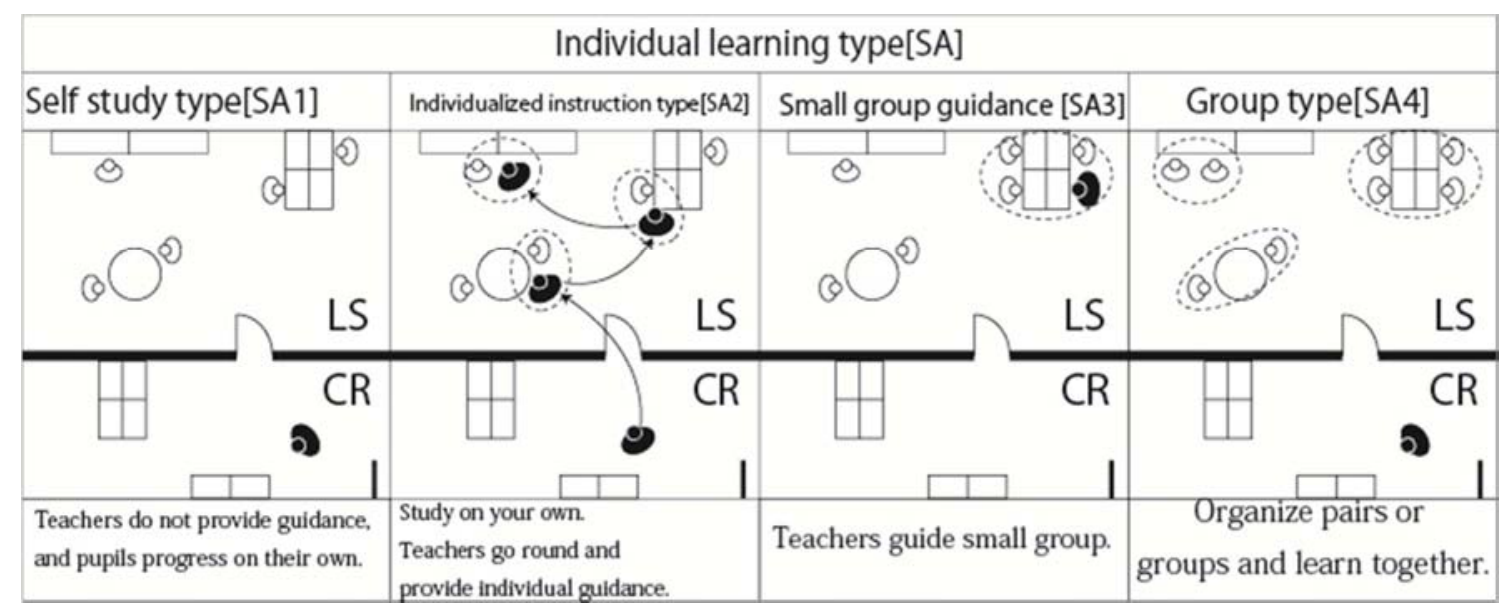

Figure 14. Types of learning system inside Learning Square.

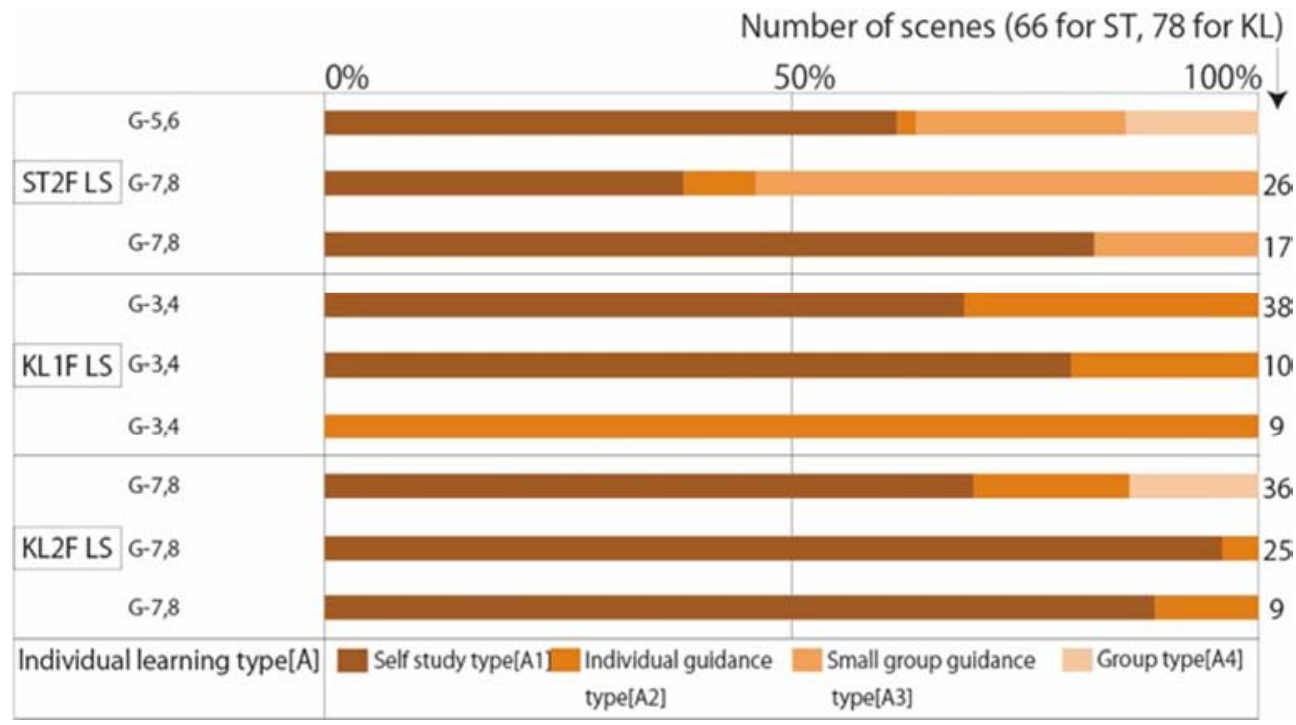

Figure 15. Ratio of learning system inside Learning Square.

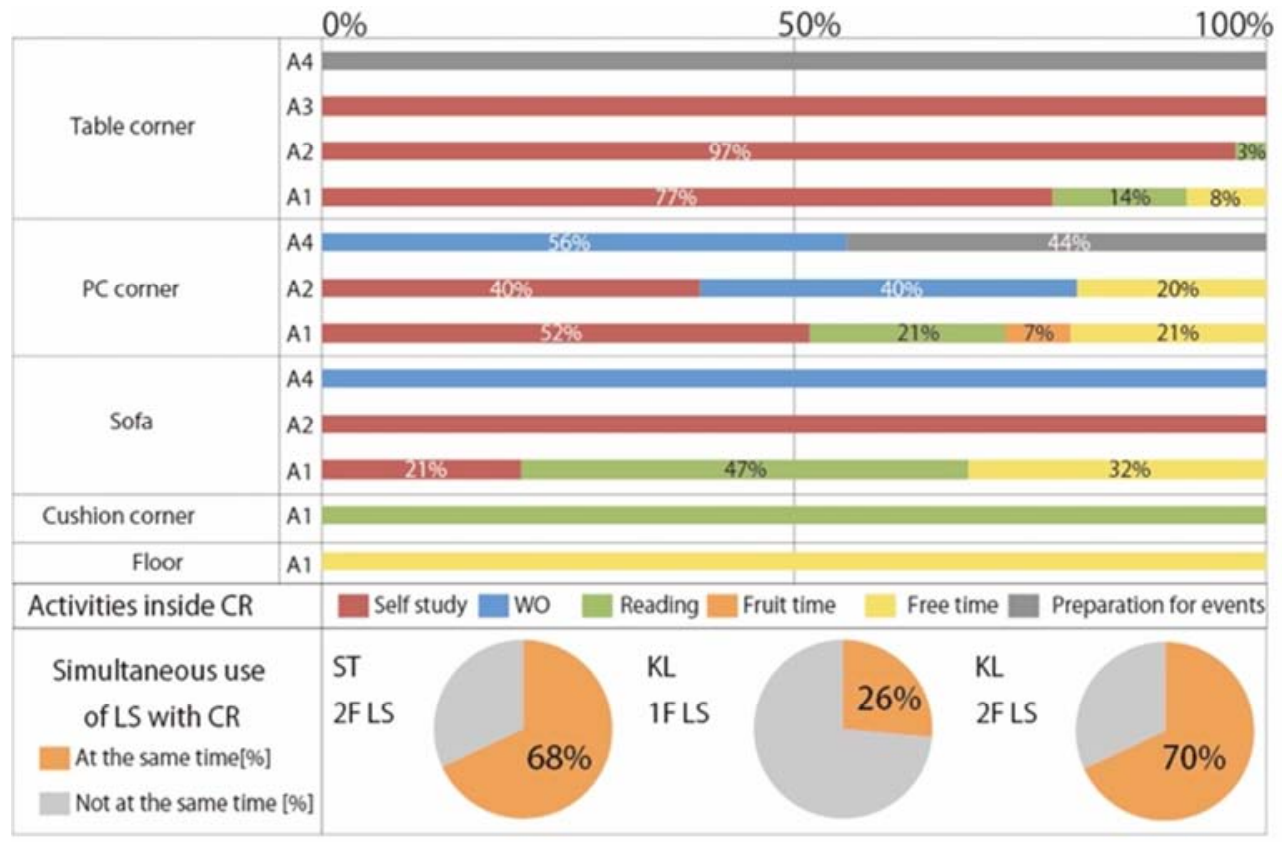

Figure 16. Ratio of learning activity in each corner. 


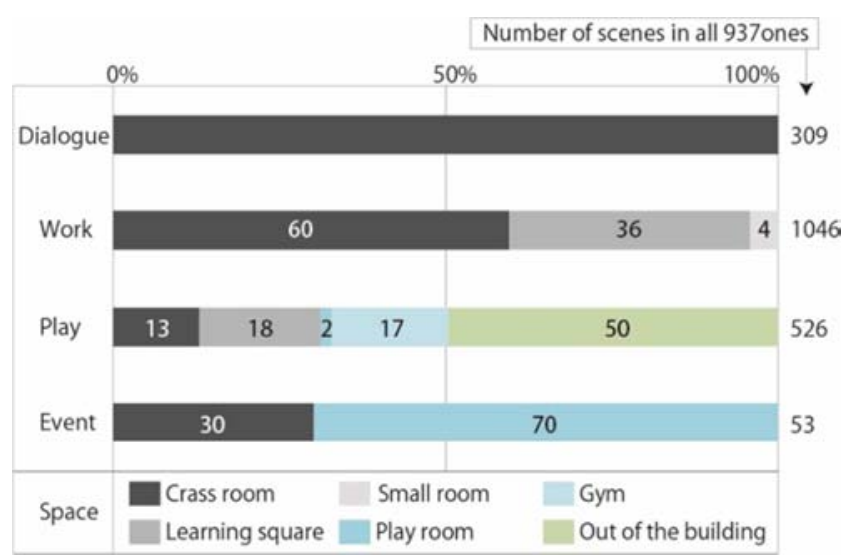

Figure 17. Ratio of learning space each learning activity.

\section{Relation Between Learning Space and Learning System in Jena Plan Education}

In this research, we conducted analysis on the learning space and form of activity in learning space pertaining to Jena Plan Education, by focusing on learning system in learning space. When we consider learning space that incorporates Jena Plan Education as 2 types of activity space comprised of classroom space and learning square in this research, we can extract specific "place" that expands learning activity and learning system comprised of learning activity in each activity space. Namely, learning activity is carried out by arranging any of "7 types of place-of-learning" inside classroom space such as blank space (floor), loft, window-side/PC section, teacher section, center table, children's seat, and circular section, and these place-of-learning linking with a total of 13 types of learning system comprised of 5 types of circular learning, 4 types of simultaneous learning, and 4 types of individual learning. Learning activity is carried out in learning square by arranging any of "5 types of place-of-learning" inside said learning square such as table section, PC section, sofa, cushion section, and blank space (floor), and these place-of-learning linking with learning system of 4 types of individual learning. All 30 types of learning activities mentioned in this research are being carried out within a relation between above place-of-learning and learning system, and various forms of activities are indicated according to their combination. Among 30 types of learning activities mentioned in this research, we will indicate correlation between place-of-learning and learning system in the below section (Figure 18), by extracting 11 types of representative learning activities. As shown in Figure, we can see that development of various learnings pertaining to learning activities of Jena Plan Education are created through connection between place-of-learning and learning system, and sometimes through linkage between activity in classroom space and learning square. It should further be noted that in the actual education field, teachers engage in their daily educational activity by selecting/practicing these learning developments at their sole discretion, according to the developmental stage and grade levels of children.

In Jena Plan Education, individualized education is being realized by teachers who select teaching method and encourage children in consideration of various learning developments obtained by relation structure indicated in the Figure, and developmental stage of each child. This kind of pedagogic circumstance in Jena Plan Education can be presented as part of next generation school education model that includes various educational methods.

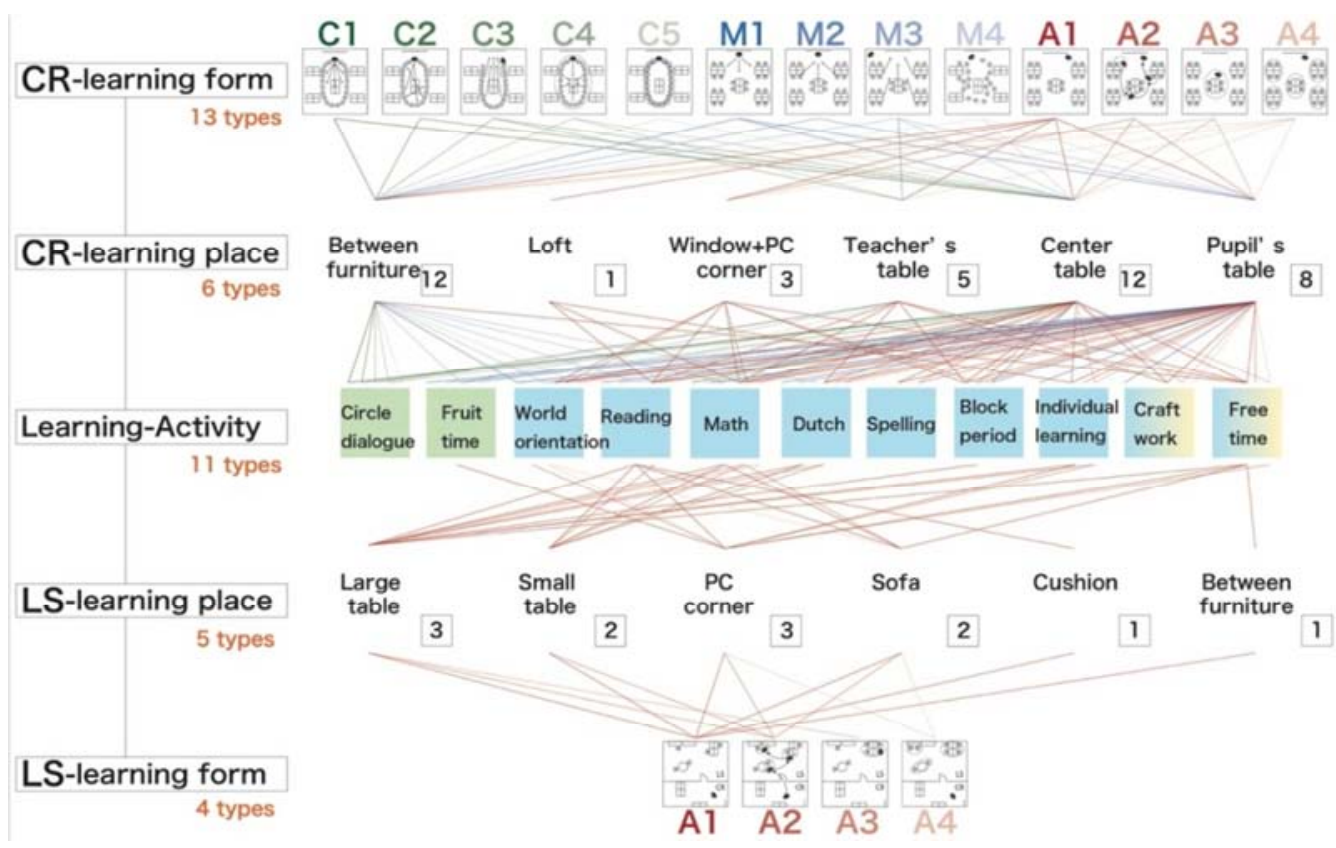

Figure 18. Relation between learning space and learning system in Jena Plan Education. 


\section{Spatial Characteristics of "Room" Type Learning Space in Jena Plan Education}

In addition to classroom space, the example analyzed in this research also comprises "unit type" learning space that combined functions such as shared space called "learning square", storage space, and bathroom. Moreover, by dividing with "Door", each space is considered "Room" independent from one another. We will indicate spatial characteristics of "Room" type learning space in Jena Plan Education, along with relation to education activity (Figure 19) in the below.

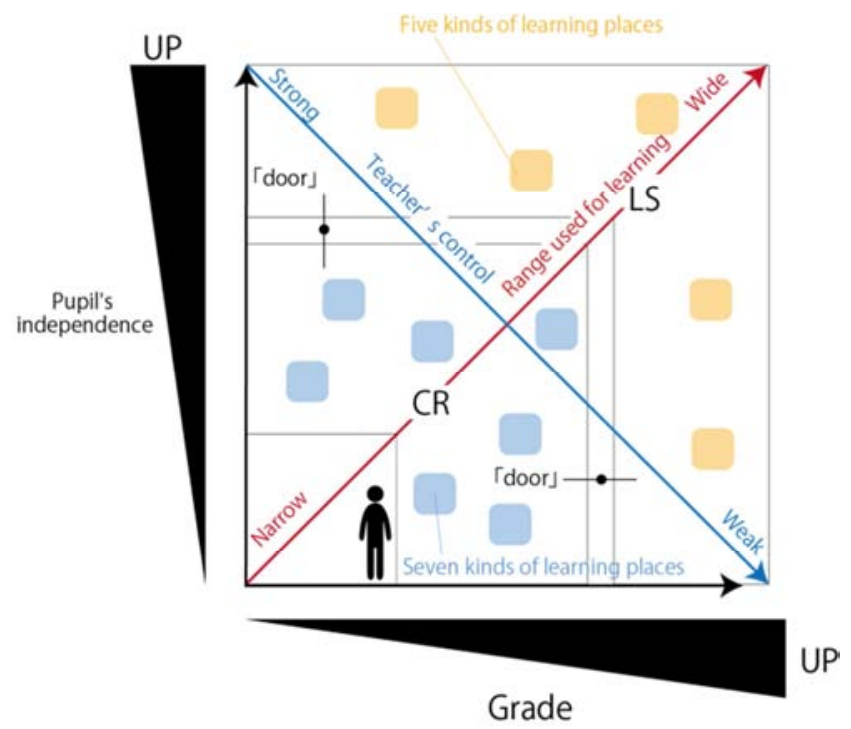

Figure 19. Spatial characteristics of "Room" type learning space.

1. Creating various place-of-learning through furniture placement

Since linkage between space for "Room" type learning space is made through minimum operation called "Door", more abundant vertical plane (wall surface, opening side) can be secured for shared space, compared to learning space of open space type in Japan. By depending on such operation, various types of furniture are being placed in shared space called "Learning square" equipped with this abundant vertical plane. By placing various types of furniture in "One room" space in which perimeter is surrounded by vertical plane, learning square transforms into learning space equipped with various places that accelerate independent learning of children required by Jena Plan Education.

We can say that "Room" type shared space (learning square) in Jena Plan Education, is effective spatial planning method in creating various place-of-learning for children in spatial level outside of classroom space.

2. Accelerating children's independence / independent learning. For "Room" type learning space, all spaces including classroom space and learning square are divided (connected) by "Door". For this reason, each learning space mutually maintains independent condition during normal time. "Independence" seen in this kind of "Room" type learning space functions effectively, when children engage in learning independent from teacher (independent learning). The analysis result of this research shows that linked rate between use rate of learning square and activity inside classroom increases as school year moves up, and at the same time confirms that children's degree of independence from teacher in learning square also increases. In other word, when upper grade children use learning square, it functions as a space where children engage in learning by themselves without teacher's presence. In doing so, by creating linkage between space through "opening and closing of door" instead of by open type as adopted in Japanese open space, a physical boundary line is created between classroom space and learning space, thus we can consider such linkage to result in minimization of teacher's involvement in learning square. Given the above, we consider spatial linkage relations between "Room" type learning space and learning square to be effective spatial planning method that accelerates children's independence/independent learning in learning square.

\section{Conclusion- Important Planning Points Regarding Classroom Space in Jena Plan Education}

1. Children's seat should be comprised with children in different age group (ideally, comprise 1 group with 4 children)

2. Place table used for instruction or children's seat in the center of classroom, and by centering around these furniture, secure blank space (floor area) to carry out circle conversation.

3. Arrange remaining seats in a way that surrounds blank space for circle conversation, by placing them near vertical plane as much as possible in a circular form. In doing so, make sure to place them in a way so that children can see blackboard from each seat as much as possible.

The above items are listed as the minimum point to remember, when planning the learning space to carry out Jena Plan Education. For the actual planning, in addition to the above pedagogical requirements, one needs to engage in planning that entails, among others, meeting architecture oriented requirements such as installation of vertical plane, scale of classroom, etc., meeting various social requirements such as the number of children, opinions of teachers, children and guardians, etc. However, classroom space established in consideration of such conditions is recognized as one of already completed architectural condition, upon implementing Jena Plan Education. 


\section{Acknowledgements}

First of all, we should like to express my deepest gratitude to Dr. ir. S. Komossa, my supervisor, for constant encouragement and guidance throughout many documents.

We are extremely grateful to the schools and teachers for the research.

\section{References}

[1] Japanese ministry of education, https://www.mext.go.jp/content/20200227-mxt_kyoiku02-100 002604_1.pdf, March 2020.

[2] Japanese ministry of education, https://www.mext.go.jp/en/about/pablication/_icsFiles/afieldf ile/2019/03/13/1374478_001.pdf, March 2020.

[3] "Netherlands: Fundamental Principles and National Policies." https://eacea.ec.europa.eu/national-policies/eurydice/content/f undamental-principles-and-national-policies-53_en, July 2020 (references).

[4] Richters N. "Why did the individual education in The Netherlands succeed?", Heibonsya, 2006 (In Japanese).

[5] Shinano Jena Plan school, https://www.jenaplanschool.ac.jp/, March 2020 (references).

[6] Petersen, P., "Der Kleine Jena-Plan", 52th Edition, Weinheim Basel: Beltz, 1972.
[7] S. J. C. Freudenthal-Lutter, "Naar de basisschool van morgen" 3de druk, Samson Uitgeverij, 1975.

[8] Nederlandse Groundwet: Artikel 23: Het openbaar en bijzonder onderwijs

http://www.denederlandsegrondwet.nl/9353000/1/j9vvihlf299 q0sr/via0istdc4zt, March 2020 (references).

[9] Nederlandse Jenaplan vereniging, NJPV: Verzamellijst buitenlandse scholen met Jenaplanverwantschap Versie: $1-7-2010$.

[10] "De 20 Jenaplan-principes op een rij," http://vlinder.niveservices.nl/files/jenaplanprincipes.pdf, March 2020 (references).

[11] Sien van Dam, Susanne Komossa, Lidwine Spoormans,"The transformation of the school building", Thoth Publisher, 2011.

[12] Dolf Broekhuizen \& Andre Mol (Author), "Scholenbouwatlas", nai010, 2015.

[13] Better visualize quality of broad schools, https://www.kinderopvangtotaal.nl/kwaliteit-brede-scholen-be ter-in-beeld-brengen-1629880w/, March 2020 (references).

[14] Herman H., "Space and Learning Lessons in Architecture 3", 010, 2008.

[15] Herman H. \& Abram S., "The Schools of Herman Hertzberger", 010, 2009. 